\title{
COLOUR CULTURE AND IDENTITY: INFLUENCE OF COLOURS ON KERALA MURAL ART
}

\section{Sandhya Ravi}

Assoc. Prof. Dr., KLE’s Fashion Technology and Apparel Institute, sandhyaravi1206@gmail.com

\begin{abstract}
The word 'mural' is derived from the Latin word 'murus', meaning 'wall'. Murals refer to paintings embellished on visual components like the wall, ceiling, or other huge lasting surfaces. The murals of Kerala unfathomably stand out for their prominence in beauty, clarity and symmetry with unmatchable linear accuracy. The tradition of mural painting in Kerala is unique in the world, and it is extremely rich with symbolism. Made only with natural mineral pigments, the colours represent the qualities of the three gunas- sattva, rajas and tamas. Sattva is purity, which is usually represented by the colour green; the figures painted with green are those for whom knowledge is the chief characteristic. Those in whom rajas, the spur to activity, is predominant, are painted in golden yellow. Tamas, inertia, the least pure is, curiously, represented by white. The traditional colours used in this art are red ochre, yellow, green, blue, white and black. Sometimes blue is also used. This traditional style mural art form uses natural pigments and vegetable colours. The subjects for the painting, derived from various Vedic texts, are not a fanciful representation but drawn from the description in the invocatory verses or dhyana slokas. Flora and fauna and other aspects of nature are pictured as backdrops, in highly stylized manners.
\end{abstract}

Keywords: Mural, Painting, Natural, Style, Vegetable colour, Vedic Texts

\section{INTRODUCTION}

The word 'mural' is derived from the Latin word 'murus', meaning 'wall'. Murals refer to paintings embellished on visual components like the wall, ceiling, or other huge lasting surfaces. The murals of Kerala unfathomably stand out for their prominence in beauty, clarity and symmetry with unmatchable linear accuracy. ${ }^{1}$ The tradition of mural painting in Kerala is unique in the world, and it is extremely rich with symbolism. Made only with natural mineral pigments, the colours represent the qualities of the three gunas- sattva, rajasandtamas.Sattvais, purity, which is usually represented by the colour green; the figures painted with green are those for whom knowledge is the chief characteristic. Those in whom rajas, the spur to activity, is predominant, are painted in golden yellow. Tamas, inertia, the least pure is, curiously, represented by white. The traditional colours used in this art are red, yellow ochre, green, blue, white and black. The traditional style mural art form uses natural pigments and vegetable colours. But, today the colours used are synthetic colours which are bright.

${ }^{1}$ Dhamija, R. (1988). Sixty Years of Writing on Art \& Crafts in India: From Roopa-Lekha, 1928-1988. New Delhi: Sterling Publishers. 
The subjects for the painting are derived from various Vedic texts, are not a fanciful representation but drawn from the description in the invocatory verses or dhyana slokas. ${ }^{\dagger}$ Flora and fauna and other aspects of nature are pictured as backdrops, in highly stylized manners.

The line drawing is made initially on the prepared fabric and subsequently the five colours are applied. The entire process of mural painting involves meticulous balancing of various components. The great and distinctive art displayed in these paintings reveal a wonderful vitality and intensity of feeling, meditative charm, divine majesty, decorative delicacy, unique verisimilitude, subtle charm of colour, fine texture and marvellous draughtsman ship.

\section{ORIGIN OF MURALS}

Simplicity of subjects, technical excellence, thematic presentation, bold but delicate strokes, bright and beautiful colours, idealistic reproduction of humans, animals and trees are what characterize Kerala Murals. It brings out a certain depth of human feelings of passion and spiritual endeavour. In conception and composition, the murals have attained its highest artistic excellence. The dignified poise of the figures with expression of the faces that is so graceful yet dynamic is an important feature in a Kerala Mural.

The great and distinctive art displayed in these paintings reveal a wonderful vitality and intensity of feeling, meditative charm, divine majesty, decorative delicacy, unique verisimilitude, subtle charm of colour, fine texture and marvellous draughtsmanship. ${ }^{2}$

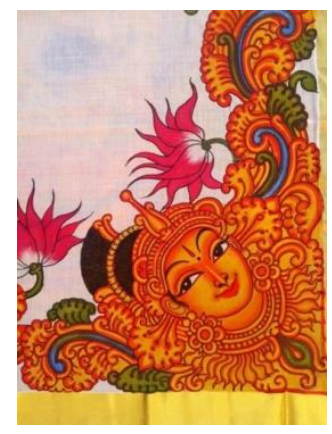

Fig 1: Mural Painting on fabric

\section{COLOURS AND TECHNIQUES}

Panchvarna the five colours yellow, red, green, black and white make up the colour scheme of Kerala Murals. They are prepared from mineral pigments and vegetables. The yellow and red colours are from minerals; green from juice of a plant locally called Eravikkara, black from the soot of oil lamps and white remains the base, which is prepared with lime. The blending of the colours is done in a wooden bowl with tender coconut water and exudes from neem tree. ${ }^{3}$ There are at least six stages before a Kerala Mural Painting is complete. Lekhya Karma is the first stage where sketching by pencil or crayon is done. The second stage is the Rekha Karma which enhances the outlines of the sketching done. The third stage called Varna Karma breathes life into the painting with its colours. Here all colours are appropriately filled in. The colouring of the human figures is done according to the characters and their common virtues. The divine and noble characters (Saatvik) are painted in green, those inclined towards power and wealth (Raajasik) is painted in shades of red, lowly mean characters (tamasik) in white and demons in black. In the fourth stage or the Vartana Karma, shading is done. Fifth stage called the Lekha Karma brings us to the final outline of the painting which is usually in black. The final and the finishing touches stage are called Dvika Karma. ${ }^{4}$

Originally, three types of brushes were made and used: flat, medium and fine. Flat brushes were made from the hairs behind calves' ear, the medium from the bottom of goats belly and the fine brush from delicate blades of grass. However in due course of time and change, use of easily available brushes from commercial market

\footnotetext{
2 Sarkar, H. (1978). An Architectural Survey of Temples of Kerala. New Delhi: Archaeological Survey of India.

${ }^{3}$ Nayar, T. S., Binu, S., \& Pushpangadan, P. (1999). "Uses of Plants and Plant Products in Traditional Indian Mural Paintings". Economic Botany. 53, 1, 41-50.
}

${ }^{4}$ www.kalakeralam.com/finearts/murals.htm 
and shading of the original colours can be distinctively noticed. ${ }^{5}$ The use of blue colour is also noticed over the passage of time. The paintings have been brought down from the walls to plywood, cloth, paper and other frames for easy to make and use purposes.

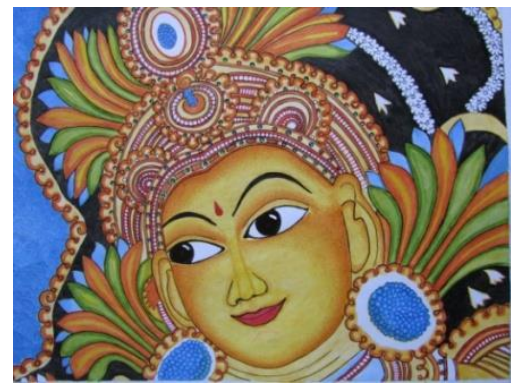

Fig 2: Colours used for Mural Painting

\section{METHODOLOGY}

The methods of mural painting of Kerala are described in chithrasoothram of Vishnudharmottara of the VI century. Tantra samuchaya the XV century text authored by Narayanan describes the importance of techniques of colour preparation, colour combination, themes for presentation and brush making. Kerala murals have its origin in the temple walls and thus a study of Kerala murals is not complete without pondering on the architecture of Kerala and its association with the murals. ${ }^{6}$

\section{PREPARATIONS OF THE PIGMENTS}

The preparation of the fabric and colour as well for mural painting is at most importance. The colour used in traditional mural paintings of Kerala is generally obtained from three different sources, mineral vegetal and chemical. All colours cannot be used in murals. The five colours ocher yellow, red, green, black and Persian blue used were prepared from stones and leaves in olden days, but, they are now readily available over the counter. ${ }^{7}$ The fabric is tightly fixed to a harite, so that, it is held firmly or it can be laid flat on the floor using brown paper or newspaper. The fabric is prepared; the pictures are drawn first in lines and then coloured. Colours are applied in a sequence such as ocher yellow, red, green, blue and black must be clearly demarketed by black lines.

\section{APPLICATION OF COLOUR}

In the traditional method a pencil called kattalekhini is prepared by grinding a black stone and mixing it with cow dung nowadays, we use different methods including the commercially available pencils. Colouring of the design goes by their virtue the spiritual, divine and dharmik characters (satvika) are depicted in shades of green those influence towards power materialistic wealth (rajas) are painted in shades of red to golden yellow. The evil, wicked and mean characters (tamas) are generally painted in black or white. Green and blue colours are to be painted only after applying the yellow ochre. ${ }^{8}$ Direct sketching of outline can be done using yellow ochres recoating of yellow is done wherever it is needed to get the satisfactory colour. The outline sketch alone is repeated in red, wherever yellow is to be shaded it is done with red. Shading is done using doting technique. All the outlines done in yellow and red are again drawn in black after painting, if there are gaps between the shades then dot shades are used to give a good finish. Dot shades gives some kind of beauty to the murals. The spaces where black is anticipated would first get painted in red which would intensify the black colour. Whatever may be the colour, the shading is done from outside inwards by dotting method.

\footnotetext{
${ }^{5}$ Panikkar, T. K. G. (1995). Malabar and Its Folk. New Delhi; Madras: Asian Educational Services.

${ }^{6}$ Nārāyaṇappaṇikkar, K. (1991). Folklore of Kerala. New Delhi: National Book Trust, India.

${ }^{7}$ www.kalakeralam.com/finearts/murals.htm

${ }^{8}$ www.artkerala.com
} 

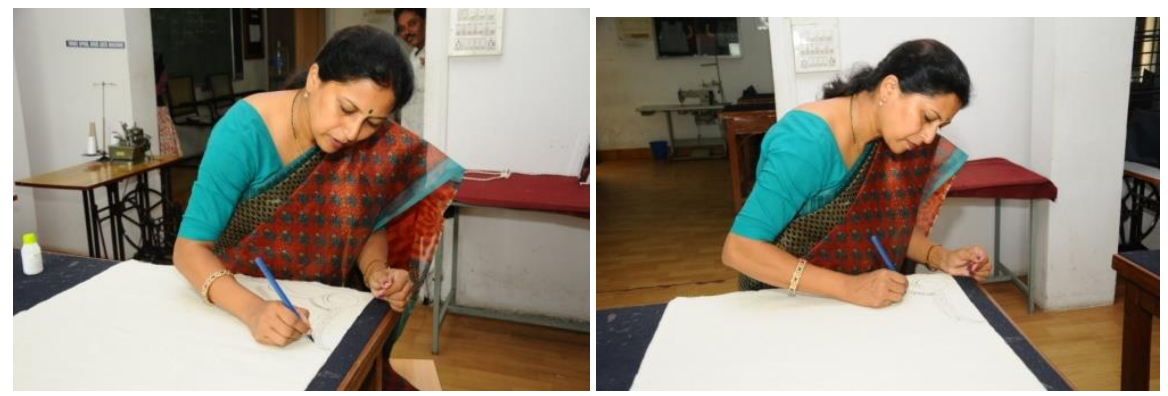

Fig 3: Outlining of the design on to the fabric Fig 4: Outlining of the design on to the fabric

The traditional methodology of drawing mythical figures on the fabric, using natural pigments, which is called Kalam (Kalamezhuthu). This ritual art is practiced in temples and sacred grove of Kerala with symbolizing the idols like Kali, Lord Ayyappa, etc which are made on the floorings, which is now transferred on to a fabric commonly using five colours.

There are about six stages to Kerala Mural paintings, they are as

1. First Stage: Lekhya Karma --On a white background fabric, first comes the sketching by pencil or crayon where the deft lines of the artist bring out the contours and curves of the motifs.

2. Second Stage: Rekha Karma which enhances the outlines of the sketching done

3. Third Stage: Varna Karma -breathes life into the painting with its colours. Here all colours are appropriately filled in. The colouring of the human figures is done according to the characters and their common virtues. The divine and noble characters (Saatvik) are painted in green, those inclined towards power and wealth (Raajasik) is painted in shades of red, lowly mean characters (tamasik) in white and demons in black.

4. Fourth Stage: the Vartana Karma, shading is done.

5. Fifth Stage: the Lekha Karma brings us to the final outline of the painting which is usually in black.

6. Sixth Stage: Dvika Karma, the final and the finishing touches are done to the painting. ${ }^{9}$

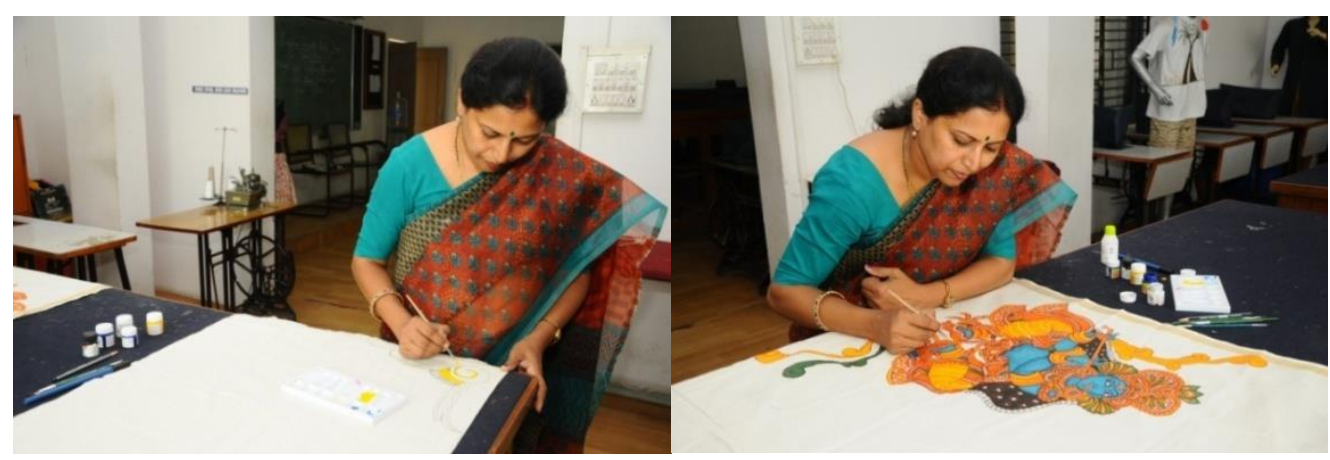

Fig 5: Application of yellow background on to the fabric

Fig 6: Application of different colours on to the design

\section{FINISHING OF THE PAINTED FABRIC}

The mural painted fabric is allowed to dry for 24 hours. The painted fabric is reversed and heat pressed in order to fix the colour. ${ }^{10}$ The temperature of the heat press depends according to the type of the base fabric. In case of cotton, the temperatures ranges between $50^{\circ} \mathrm{C}$ to $75^{\circ} \mathrm{C}$ and if the fabric used for the mural painting is silk then the temperature ranges between $30^{\circ} \mathrm{C}$ to $40^{\circ} \mathrm{C}$.

${ }^{9}$ Vijayakumār, M. (2006). A Brief Survey of the Art Scenario of Kerala. Kariavattom: International Centre for Kerala Studies.

10 İbid. 


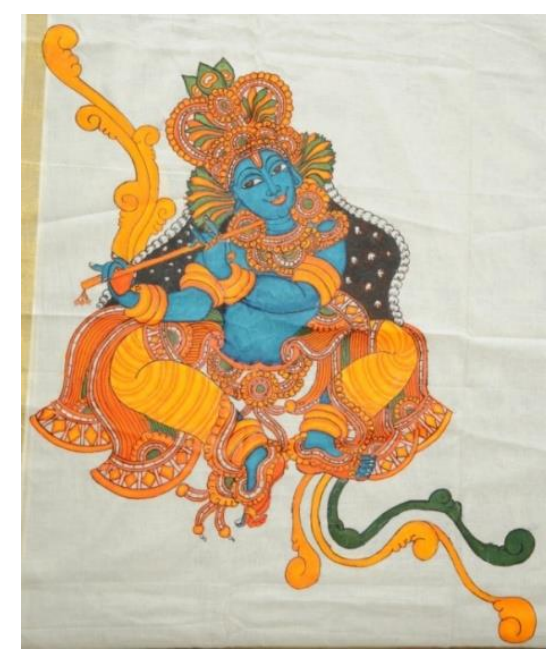

Fig 7: Finished Mural art on Fabric

\section{RESULTS AND DISCUSSIONS}

The art created were subjected to consumer acceptability with respect to colour and concept and it was done by questionnaire method. 100 respondents were selected for evaluating the questionnaire.

Consumer Acceptability with respect to Colour

\begin{tabular}{|l|l|l|l|l|l|}
\hline Criteria & Excellent & Very Good & Good & Satisfactory & Poor \\
\hline Design 1 & 80 & 10 & 5 & 5 & - \\
\hline Design 2 & 82 & 9 & 4 & 5 & - \\
\hline Design 3 & 79 & 12 & 4 & 5 & - \\
\hline Design 4 & 65 & 15 & 20 & - & - \\
\hline
\end{tabular}

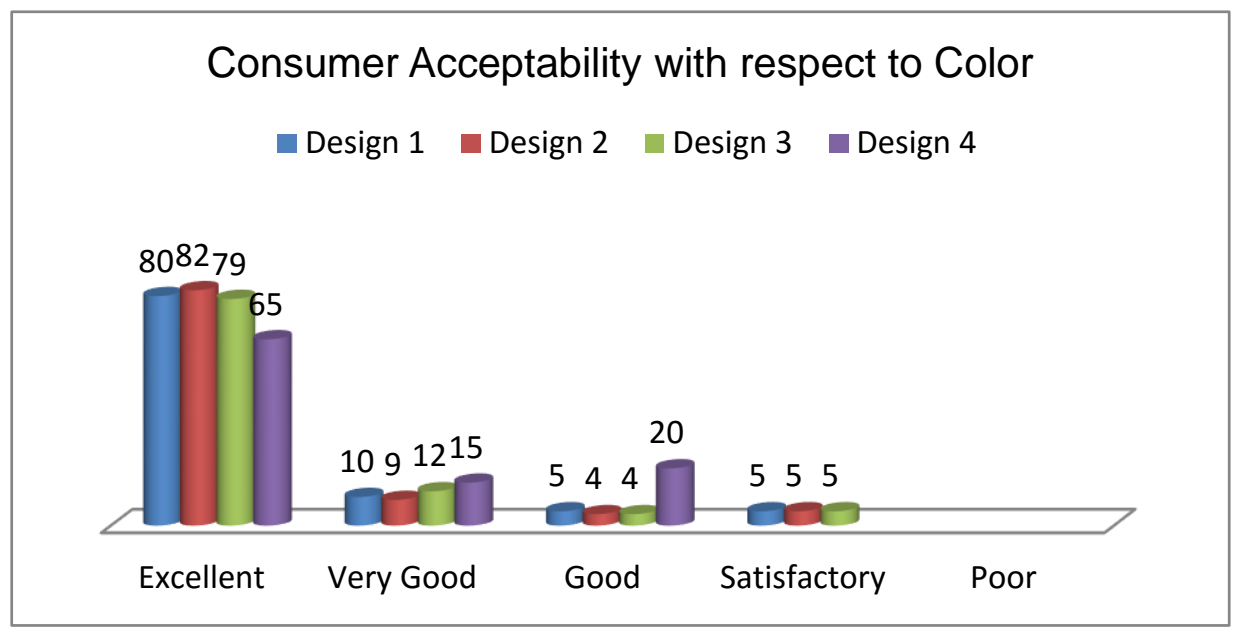

The above graphical representation clearly depicts that colours used are bright and appropriate with equal distribution and shading of colours with respect to design. The respondents were of the opinion that the painting was very attractive and eye catching with perfect blend of collars and there shades. 
Consumer Acceptability with respect to Concept

\begin{tabular}{|l|l|l|l|l|l|}
\hline Criteria & Excellent & Very Good & Good & Satisfactory & Poor \\
\hline Design 1 & 82 & 8 & 5 & 5 & - \\
\hline Design 2 & 84 & 12 & 4 & - & - \\
\hline Design 3 & 81 & 11 & 6 & 2 & - \\
\hline Design 4 & 78 & 15 & 5 & 2 & - \\
\hline
\end{tabular}

Consumer accepatability with respect to Concept

a Design $1 \quad$ Design $2 \quad$ Design $3 \quad$ Design 4 8284818
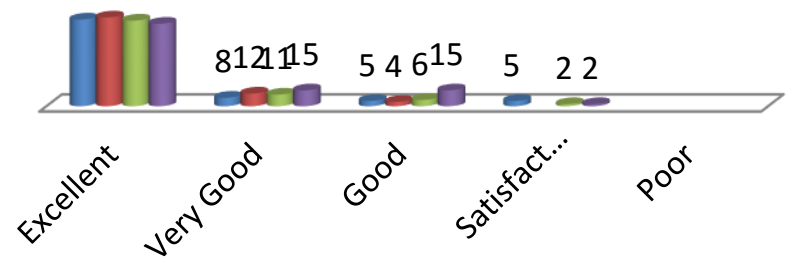

The above graphical representation clearly depicts that the concept of combination of five colours in mural painting based on mythological characters were well accepted by the respondents and they were of the opinion that the concept of design and colour were beautifully blended with clear expression and clarity. ${ }^{11}$

\section{CONCLUSIONS}

Modernization has influenced the art and artist to a large extent. In olden days these mural paintings were painted on the walls of temples, palaces and churches, now, it can be done on any surface, like paper, canvas, TFT boards and are being tried on terracotta. ${ }^{12}$ The mural art drawings or designs have retained their traditional styles, all though the medium has been shifted to synthetic paints instead of natural colours. This change is due to the time consuming preparation of the pigments and availability of raw materials in the market. The unique feature noted in the mural is the excellent colour combination which influences the overall aesthetic appeal. The entire process of mural involves meticulous balancing of various components. The art displayed in these paintings reveal a wonderful vitality and intensity of feeling, meditative charm, divine majesty, decorative delicacy, unique verisimilitude, subtle charm of colours, fine texture and marvellous creativity. ${ }^{13}$

\section{REFERENCE LIST}

Sarkar, H. (1978). An Architectural Survey of Temples of Kerala. New Delhi: Archaeological Survey of India.

Nārāyaṇappanikkar, K. (1991). Folklore of Kerala. New Delhi: National Book Trust, India.

Vijayakumār, M. (2006). A Brief Survey of the Art Scenario of Kerala. Kariavattom: International Centre for Kerala Studies.

Nayar, T. S., Binu, S., \& Pushpangadan, P. (1999). "Uses of Plants and Plant Products in Traditional Indian Mural Paintings". Economic Botany. 53, 1, 41-50.

Dhamija, R. (1988). Sixty Years of Writing on Art \& Crafts in India: From Roopa-Lekha, 1928-1988. New

\footnotetext{
${ }^{11}$ www.kalakeralam.com/finearts/murals.htm

12 Sivaramamurti, C. (1970). Indian Painting. New Delhi: National Book Trust).

${ }^{13}$ Sarkar, H. (1978). An Architectural Survey of Temples of Kerala. New Delhi: Archaeological Survey of India.
} 
Delhi: Sterling Publishers.

Sivaramamurti, C. (1970). Indian Painting. New Delhi: National Book Trust).

Panikkar, T. K. G. (1995). Malabar and Its Folk. New Delhi; Madras: Asian Educational Services.

www. ker a l a. co m / ke r a l a r t s / h t m I/fineart.html

www.artkerala.com

www.kalakeralam.com/finearts/murals.htm

www.keralamurals.com

www.orgpeople.com/org.projects/murals

www.templenet.com/arts/murals.html 